\title{
Efficient introduction of alkene functionality into proteins in vivo
}

\author{
Jan C.M. van Hest, David A. Tirrell* \\ Department of Polymer Science and Engineering, University of Massachusetts, Amherst, MA 01003, USA
}

Received 9 March 1998; revised version received 9 April 1998

\begin{abstract}
The methionine analogue 2-amino-5-hexenoic acid (homoallylglycine, Hag) can be utilized by Escherichia coli in the initiation and elongation steps of protein biosynthesis. Use of an E. coli methionine auxotroph and Hag-supplemented medium resulted in replacement of ca. $85 \%$ of the methionine residues in mouse dihydrofolate reductase expressed under control of a bacteriophage $\mathbf{T 5}$ promoter. $\mathrm{N}$-terminal sequencing indicated $92 \pm 5 \%$ occupancy of the initiator site by Hag. The vinyl function of Hag remains intact in the purified protein and suggests new chemistries for modification of natural and artificial proteins prepared in bacterial hosts.
\end{abstract}

(C) 1998 Federation of European Biochemical Societies.

Key words: Chemical modification; Protein engineering; Amino acid analogue; Homoallylglycine; Methionine replacement

\section{Introduction}

Protein engineering constitutes a powerful tool for modification of the structural, catalytic and binding activities of natural proteins and for the de novo design of novel macromolecular materials [1-4]. At the same time, the specificity of protein biosynthesis limits the scope of in vivo engineering methods, in that the pool of potential monomers is restricted to the natural proteinogenic amino acids and those analogues that can be activated and charged to transfer RNAs. The number of analogues shown conclusively to exhibit translational activity in vivo is small, and the range of chemical functionality accessible via this route remains modest. The introduction of new building blocks for protein synthesis, and in particular, of new functional groups with novel patterns of reactivity, will expand significantly the scope and impact of protein engineering methods.

Several analogues of methionine (1) (specifically selenomethionine [5], telluromethionine [6], norleucine [7], trifluoromethionine [8] and ethionine [9]) have been shown to exhibit translational activity in bacterial hosts. These results turned our attention to homoallylglycine (Hag, 2), which we anticipated might serve as a vehicle for the introduction of reactive terminal alkene functionality into proteins made in vivo. Hag has been exploited to effect 'covalent capture' of hydrogenbonded peptide dimers via ruthenium-catalyzed olefin metathesis [10], and the versatile chemistry of alkenes [11] suggests other novel approaches to the derivatization of Hag residues in engineered proteins. Although Hag has recently been isolated by ethanol extraction of the fruit body of the fungus Amanita gymnopus [12], we are unaware of previous studies of the in vivo translational activity of any of the aminohex-

\footnotetext{
*Corresponding author. Fax: (1) (413) 5771610.

E-mail: tirrell@polysci.umass.edu
}

enoic acids. We show herein that Hag functions efficiently as a methionine surrogate in the initiation and elongation steps of protein synthesis in Escherichia coli<smiles>CSCCC(N)C(=O)O</smiles>

1<smiles>C=CCCC(N)C(=O)O</smiles>

2

\section{Materials and methods}

\subsection{Synthesis of $\mathrm{Hag}$}

DL-Hag was prepared by alkylation of diethyl acetamidomalonate with 3-butenyl tosylate followed by hydrolysis to the amino acid [13,14]. NMR data obtained for Hag were in agreement with [12]. Similar methods were used for synthesis of the cis- and trans-2-amino-4-hexenoic acids.

\subsection{Determination of translational activity}

A bacterial host (designated CAG18491/pREP4/pQE15) suitable for testing the translational activity of $\mathrm{Hag}$ and its internal isomers cisand trans-2-amino-4-hexenoic acids ( $\mathbf{3}$ and $\mathbf{4}$, respectively) was prepared by transformation of E. coli strain CAG18491, a methionine auxotroph, with the repressor plasmid pREP4 and the expression plasmid pQE-15 (QIAGEN, Inc., Santa Clarita, CA, USA). pQE-15 encodes mouse dihydrofolate reductase (mDHFR) under control of a bacteriophage T5 promoter, as well as an N-terminal hexahistidine sequence that facilitates purification of the protein by immobilized metal affinity chromatography. mDHFR contains seven methionine residues, each a potential site for substitution of methionine by the aminohexenoic acids<smiles>C/C=C\CC(N)C(=O)O</smiles>

3<smiles>C/C=C/CC(N)C(=O)O</smiles>

4
The translational activity of the aminohexenoic acids was investigated on a $5-\mathrm{ml}$ scale. A CAG18491/pREP4/pQE15 culture was grown in M9AA medium supplemented with glucose, thiamine, $\mathrm{MgSO}_{4}$ and the antibiotics kanamycin and ampicillin, until the optical density of the culture $\left(\mathrm{OD}_{600}\right)$ reached a value of 0.9 . Cells were sedimented by centrifugation and resuspended in the same medium, without methionine. Negative (no methionine or analogue added after the medium shift) and positive (addition of $40 \mathrm{mg} / 1(0.27 \mathrm{mM})$ methionine) controls were performed. In order to test translational activity, the analogue of interest was added to the medium at a concentration of 40 $\mathrm{mg} / \mathrm{l}(0.31 \mathrm{mM})$, and protein expression was induced by addition of $0.4 \mathrm{mM}$ isopropyl $\beta$-D-thiogalactopyranoside (IPTG). Cell growth and protein expression were followed over a 4 -h period. 


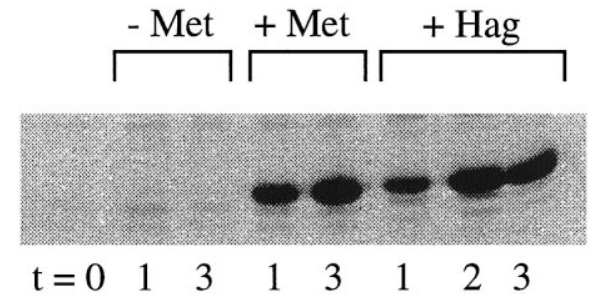

Fig. 1. Identification of mDHFR and mDHFR-E by SDS-polyacrylamide gel electrophoresis. $t=0$ : time of induction by addition of 0.4 $\mathrm{mM}$ IPTG; $t=1: 80 \mathrm{~min}$ after induction; $t=2: 2.5 \mathrm{~h}$ after induction; $t=3: 4 \mathrm{~h}$ after induction. Lane 1: no induction; lanes 2-3: M9AA medium without L-methionine or Hag; lanes 4-5: M9AA medium supplemented with $0.27 \mathrm{mM}$ L-methionine; lanes 6-8: medium supplemented with $0.31 \mathrm{mM}$ DL-Hag.

\subsection{Isolation of alkene-substituted mDHFR}

The procedure described above was repeated on a 1-1 scale. After $3 \mathrm{~h}$ the cells were harvested, and the target protein (mDHFR-E) was purified by immobilized metal affinity chromatography. mDHFR-E eluted in the $\mathrm{pH} 4.5$ ( $8 \mathrm{M}$ urea) wash, and was isolated by dialysis against distilled $\mathrm{H}_{2} \mathrm{O}$ followed by lyophilization.

\section{Results and discussion}

CAG18491/pREP4/pQE15 cultures were grown in M9AA medium, sedimented by centrifugation, and resuspended in the test medium, which contained either: (i) no methionine or analogue (negative control); (ii) methionine (positive control); or (iii) the analogue of interest. Expression of mDHFR was induced by addition of IPTG, and cell growth and protein synthesis were followed over a 4 -h period. No induction was observed in the negative control culture or in cultures supplemented with either of the 2-amino-4-hexenoic acids. On the other hand, supplementation of CAG18491/pREP4/ pQE15 cultures with methionine or with Hag led to appearance of new protein bands at the position expected for mDHFR in SDS-polyacrylamide gel electrophoresis (Fig. 1). Thus, of the three aminohexenoic acids tested, only Hag, the terminally-unsaturated isomer, shows significant activity as a methionine surrogate in bacterial protein synthesis. The yield of target protein (mDHFR-E) isolated from Hag-supplemented cultures was $8 \mathrm{mg} / \mathrm{l}$.

Amino acid analysis of purified mDHFR-E indicated that the protein contained $0.5 \mathrm{~mol} \%$ methionine vs. the expected value of $3.7 \mathrm{~mol} \%$. Hag is unstable under the conditions used for amino acid analysis, and could not be observed directly by this method; however, assumption that the diminution in methionine content is due to replacement by Hag leads to an estimate of $86 \pm 5 \%$ substitution by the analogue. N-terminal sequencing of mDHFR-E (which does not degrade the analogue) showed directly that $92 \pm 5 \%$ of the initiator methionine was replaced by Hag. Retention of the $\mathrm{N}$-terminal residue in both mDHFR and mDHFR-E is consistent with the known correlation between the extent of methionine excision from $E$. coli proteins and the identity of the penultimate amino acid [15].

Further evidence for incorporation of the alkene function was obtained via ${ }^{1} \mathrm{H}-\mathrm{NMR}$ spectroscopy (Fig. 2). Comparison of the alkene proton regions of the spectra of mDHFR-E (Fig. 2b and d), mDHFR (Fig. 2a) and Hag (Fig. 2c) clearly shows the vinyl $\mathrm{CH}$ resonance of $\mathrm{Hag}$ at a chemical shift of $5.7 \mathrm{ppm}$ in the spectrum of mDHFR-E. The vinyl $\mathrm{CH}_{2}$ signal is suppressed because it coincides with the HOD resonance. Integration indicates replacement of $77 \pm 5 \%$ of the methionine residues of $\mathrm{mDHFR}$.

These results demonstrate conclusively that Hag serves as a methionine surrogate in the initiation and elongation steps of protein synthesis in E. coli. In contrast, the internal alkene isomers, the cis- and trans-2-amino-4-hexenoic acids, do not support protein synthesis in the assay reported here; apparently the conformational restriction imposed on the four-carbon side chain by the planar internal double bond either (i) suppresses recognition by the bacterial methionyl-tRNA synthetase; (ii) inhibits activation or charging by the enzyme; or (iii) partitions the analogue into the editing pathway of the synthetase subsequent to activation [16,17]. Although the crystal structure of an active tryptic fragment of the synthetase (complexed with ATP) has been reported [18], the corresponding structures of the complexes with methionine or with tRNA $^{\text {Met }}$ are not yet available. Inferences concerning the

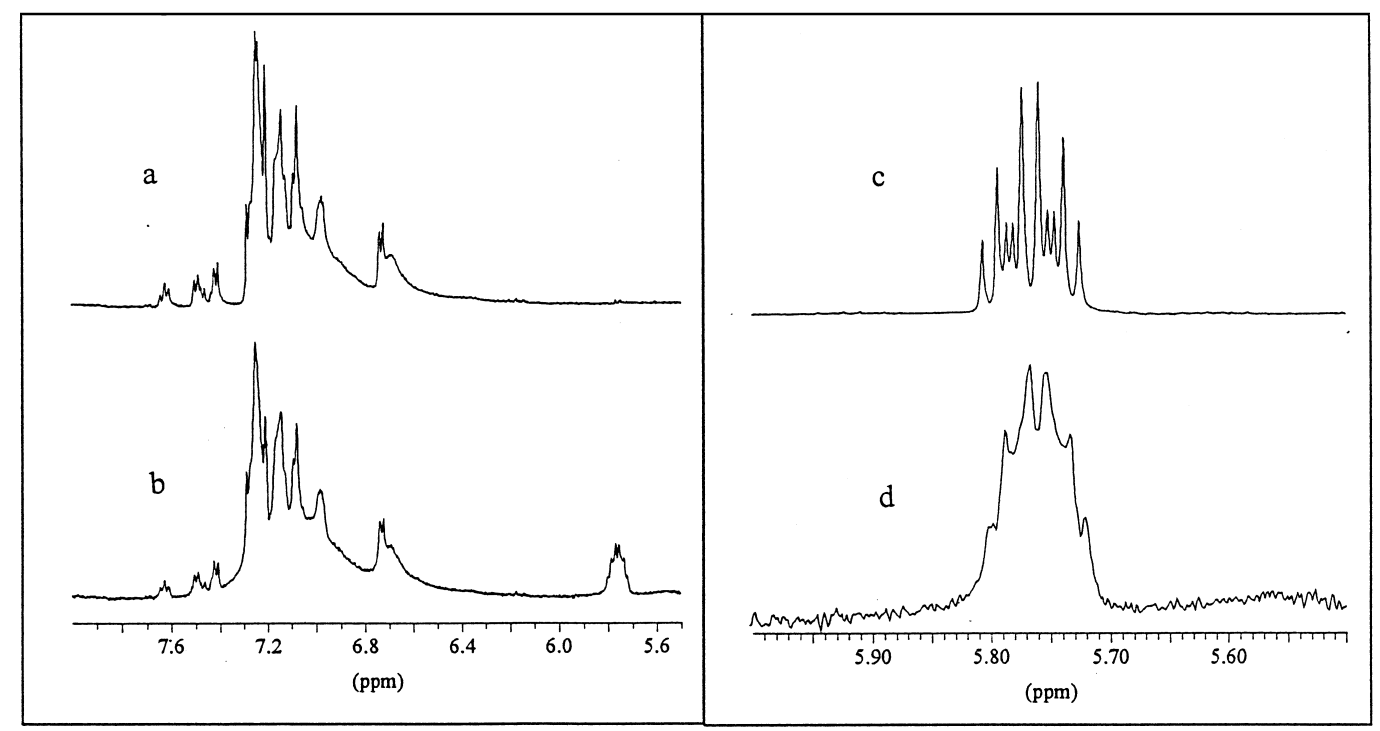

Fig. 2. ${ }^{1} \mathrm{H}-\mathrm{NMR}$ spectra $\left(\mathrm{D}_{2} \mathrm{O}, 500.13 \mathrm{MHz}\right)$ of (a) mDHFR, (b) mDHFR-E, (c) Hag and (d) mDHFR-E alkene proton region. 
mechanism of amino acid recognition must therefore be made with care, and have heretofore been made indirectly, on the basis of sequence comparison and site-directed mutagenesis $[17,19,20]$.

The observation that Hag can be incorporated into E. coli proteins in vivo creates important new opportunities for protein engineering. For example, recent advances in the chemistry of olefin metathesis have led to the development of transition metal carbenes that catalyze efficient cyclization of peptides containing $\mathrm{Hag}$ [10] or allylglycine [21], and that retain catalytic activity in aqueous media [22]. Analogous reactions on genetically engineered artificial proteins could be used for crosslinking or side-chain modification, and because Hag occupies the initiator site, for the introduction of new endgroups, tethering of chains on surfaces, or the synthesis of block copolymers. With respect to natural proteins, it remains to be shown that alkene derivatization can be accomplished without interference from reactions occurring at residues other than Hag; nevertheless, the possibilities are intriguing even for the alkene-functional proteins per se, since methionine residues have been proposed to play important roles in controlling intersubunit interactions and protein-protein recognition processes $[8,23,24]$.

Finally, we note that the method reported herein for introduction of novel functionality into proteins is complementary to the in vitro methods, involving chemical misacylation of suppressor tRNAs, under development elsewhere [25]. The in vitro approach accommodates a broader range of side-chain structures, and the use of suppressor tRNAs allows the nonnatural amino acid to be inserted at a single programmed site in the protein of interest. The in vivo method described here, on the other hand, provides substantially larger yields of the target protein, avoids the difficulties of chemical misacylation and competitive translational termination at the site of substitution, and is better suited to the synthesis of proteins modified at multiple sites, which are finding increasing use in crystallographic determination of protein structure [5]. Both methods illustrate the subtle and surprising synthetic versatility of the protein biosynthetic apparatus of bacterial cells.

Acknowledgements: The authors thank L.C. Dickinson for assistance with NMR spectroscopy and D.C. Rees for bringing to our attention References [23] and [24]. This work was supported by a grant from the Polymers and Genetics Programs of the US National Science Foundation. The Netherlands Organization for Scientific Research (NWO) and DSM-Research are acknowledged for unrestricted research grants.

\section{References}

[1] Cleland, J.L. and Craik, C.S. (1996) Protein Engineering: Principles and Practice, Wiley-Liss, New York, NY.

[2] Prince, J.T., McGrath, K.P., DiGirolamo, C.M. and Kaplan, D.L. (1995) Biochemistry 34, 10879-10885.

[3] Krejchi, M.T., Atkins, E.D.T., Waddon, A.J., Fournier, M.J., Mason, T.L. and Tirrell, D.A. (1994) Science 265, 1427-1432.

[4] Yu, S.M., Conticello, V., Kayser, C., Fournier, M.J., Mason, T.L. and Tirrell, D.A. (1997) Nature 389, 167-170.

[5] Hendrickson, W.A., Horton, J.R. and LeMaster, D.M. (1990) EMBO J. 9, 1665-1672.

[6] Boles, J.O., Lewinski, K., Kunke, M., Odom, J.D., Dunlap, B.R., Lebioda, L. and Hatada, M. (1994) Nat. Struct. Biol. 1, 283-284.

[7] Cowie, D.B., Cohen, G.N., Bolton, E.T. and De Robichon-Szulmajster, H. (1959) Biochim. Biophys. Acta 34, 39-46.

[8] Duewel, H., Daub, E., Robinson, V. and Honek, J.F. (1997) Biochemistry 36, 3404-3416.

[9] Budisa, N., Steipe, B., Demanage, P., Eckerskorn, C., Kellermann, J. and Huber, R. (1995) Eur. J. Biochem. 230, 788-796.

[10] Clark, T.D. and Ghadiri, M.R. (1995) J. Am. Chem. Soc. 117, 12364-12365.

[11] Trost, B.M. and Fleming, I., Eds. (1991) Comprehensive Organic Synthesis, Pergamon Press, Oxford.

[12] Hatanaka, S.-I., Furukawa, J., Aoki, T., Akatsuka, H. and Nagasawa, E. (1994) Mycoscience 35, 391-394.

[13] Drinkwater, D.J. and Smith, P.W.G. (1972) J. Chem. Soc. (c), 1305.

[14] Baldwin, J.E., Hulme, C. and Schofield, C.J. (1992) J. Chem. Res. (S) 173.

[15] Hirel, P.-H., Schmitter, J.-M., Dessen, P., Fayat, G. and Blanquet, S. (1989) Proc. Natl. Acad. Sci. USA 86, 8247-8251.

[16] Fersht, A.R. and Dingwall, C. (1979) Biochemistry 18, 1259.

[17] Kim, H.Y., Ghosh, G., Schulman, L.H., Brunie, S. and Jakubowski, H. (1993) Proc. Natl. Acad. Sci. USA 90, 1155311557.

[18] Brunie, S., Zelwer, C. and Risler, J.-L. (1990) J. Mol. Biol. 216, $411-424$

[19] Fourmy, D., Mechulam, Y., Brunie, S., Blanquet, S. and Fayat, G. (1991) FEBS Lett. 292, 259-263.

[20] Ghosh, G., Pelka, H., Schulman, L.H. and Brunie, S. (1991) Biochemistry 30, 9569-9575.

[21] Miller, S.J., Blackwell, H.E. and Grubbs, R.H. (1996) J. Am. Chem. Soc. 118, 9606-9614.

[22] Lynn, D.M., Kanaoka, S. and Grubbs, R.H. (1996) J. Am. Chem. Soc. 118, 784-790.

[23] Georgiadis, M.M., Komiya, H., Chakrabarti, P., Woo, D., Kornuc, J.J. and Rees, D.C. (1992) Science 257, 1653-1659.

[24] Gellman, S.H. (1991) Biochemistry 30, 6633-6635.

[25] Mendel, D., Cornish, V.W. and Schultz, P.G. (1995) Annu. Rev. Biophys. Biomol. Struct. 24, 435. 